Article

\title{
Effect of Overaging on the Cyclic Deformation Behavior of an AA6061 Aluminum Alloy
}

\author{
Kun Liu * (D), Foisal Ahmed Mirza and Xiao Grant Chen \\ Department of Applied Sciences, University of Québec at Chicoutimi 555, boulevard de l'Université, \\ Chicoutimi, QC G7H 2B1, Canada; f4mirza@ryerson.ca (F.A.M.); xgrant_chen@uqac.ca (X.G.C.) \\ * Correspondence: kun.liu@uqac.ca; Tel.: +1-(418)-545-5011 (ext. 7112); Fax: +1-(418)-545-5012
}

Received: 12 June 2018; Accepted: 4 July 2018; Published: 7 July 2018

\begin{abstract}
The present work encompasses the effect of overaging on the strain-controlled low-cycle fatigue (LCF) behavior of an extruded AA6061 aluminum alloy at varying strain amplitudes. During the T7 aging treatment, the size of precipitates increased from $60 \mathrm{~nm}$ under T6 conditions to $220 \mathrm{~nm}$ after aging for $48 \mathrm{~h}$ at $200{ }^{\circ} \mathrm{C}$, leading to a decrease in the monotonic tensile strength. During the LCF tests, nearly symmetrical hysteresis loops can be observed in the mid-life cycle under all test conditions, whereas the first-cycle hysteresis loops were moderately inflected under long-aging conditions. With increasing aging time, the cyclic peak stresses decreased and the plastic strain increased. Nearly ideal Masing behavior was exhibited under T6 conditions, while it was lost under T7 overaging conditions. The cyclic stress responses were similar under all tested conditions, involving stabilization at low strain amplitudes and softening at high strain amplitudes, with initial hardening for the first few cycles. Compared to the T6 condition, the fatigue life increased with increasing T7 aging time. Various LCF parameters were estimated based on the Coffin-Manson and Basquin relationships and on the LCF experimental results. The relationship between the fatigue life, strength, and microstructure of the investigated AA6061 aluminum alloy under various aging conditions was discussed.
\end{abstract}

Keywords: 6061 aluminum alloys; aging treatments; precipitates; cyclic deformation; fatigue life

\section{Introduction}

The 6xxx-series aluminum alloys are extensively used in the aerospace and automotive industries, owing to their ideal mechanical properties, good corrosion resistance, as well as good formability and weldability [1-4]. There is considerable industrial interest in these alloys, as two thirds of all extruded products are made of aluminum, and $90 \%$ of these are made of the 6xxx-series alloys [4]. AA6061 alloys are one of the most widely used precipitation-hardening aluminum alloys in the 6xxx series [2,3,5]. Structural components of AA6061 alloys used in engineering services would require the evaluation of their mechanical performance under cyclic loads, because these components would unavoidably experience dynamic loading in service, which leads to the occurrence of fatigue failure $[2,6,7]$. Thus, to ensure the structural integrity and durability of such engineering components, it is essential to understand the fatigue and cyclic deformation behavior of AA6061 aluminum alloys.

Several studies were conducted to understand the fatigue behavior of aluminum alloys over the years, especially on age-hardening aluminum alloys, such as the $2 x x x$ and $7 x x x$ alloys [1,2,6-16]. Haji [6] analyzed the influence of the microstructure and alloy compositions in AA2024-T6 and AA7020-T6 aluminum alloys on their cyclic deformation behavior, and found that the degree of compatibility and precipitation of $\mathrm{Zn}$ and $\mathrm{Cu}$ on their parent metal led to higher fatigue properties in the AA7020-T6 alloy than in the AA2024-T6 alloy. Lapovok et al. [12] studied the fatigue behavior of 2124 aluminum alloys, processed by equal channel angular extrusion, and reported that the low-cycle 
fatigue (LCF) life was improved owing to the grain refinement. However, the existing systematic studies on the LCF behaviors of 6xxx alloys are limited [1,2,9,13]. Wong et al. [9] conducted cyclic strain-controlled fatigue tests on an extruded 6061-T6 alloy, and Brammer et al. [1] conducted fatigue tests on an extruded 6061-T6 alloy at a fixed 5-Hz frequency at different strain amplitudes. In both cases, the tests were performed up to the maximum $0.6 \%$ strain amplitude, which was not sufficient to fully reveal the LCF behavior of the AA6061 alloys. LCF studies related to high strain amplitudes $(0.8-1.2 \%)$ and performed at different frequencies for different strain amplitudes remain to be reported in AA6061 alloys.

Heat treatment and especially aging treatment are of great significance for precipitation-hardening aluminum alloys. However, only limited research is found to investigate the influence of various heat treatments on LCF behavior, especially for 6xxx aluminum alloys. Adnan et al. [2] investigated the LCF behavior of an AA6061 aluminum alloy in three heat-treatment conditions (annealing (O), T4, and T651). It was found that the 6061-O alloy had the highest value of transition fatigue life, owing to high ductility, but little explanation on the relationship between the LCF behavior and precipitates was given. Nandy et al. [17] studied the LCF performance of an AA6063 alloy subjected to under-aged, peak-aged, and overaged conditions. It was revealed that the cyclic hardening and softening properties were quite different under the three aging conditions. The structural components of AA6061 alloys are mostly used at the peak-aged (T6) and overaged (T7) conditions. Owing to the change in precipitate characteristics (mainly the number density, size, and volume fraction), the T6- and T7-treated alloys exhibit different combinations of strength and ductility, which are expected to have a significant effect on the LCF behavior, and consequently, on the loadbearing capability and endurance of a structural component. It is, therefore, of great technical interest to investigate the cyclic stress-strain behavior, including the cyclic stress and strain response, hysteresis loops, and fatigue life of AA6061 alloys during various aging treatments. Such information on cyclic strain-controlled behavior is essential because of the potential use of the alloy in fatigue-critical and temperature-sensitive applications [2].

In the presented work, overaging treatments were performed on an extruded AA6061 aluminum alloy to investigate the effect of various degrees of overaging on LCF behavior at various strain amplitudes. The LCF behaviors under various overaging conditions were systematically analyzed using hysteresis loops, cyclic stress-strain responses, and multiple fatigue parameters, and compared to the properties under peak-aging conditions. The relationship between the precipitation, mechanical properties, and LCF performance of an AA6061 aluminum alloy was discussed.

\section{Materials and Experimental Procedure}

The material under investigation was an extruded AA6061 aluminum alloy with a chemical composition as given in Table 1 . The material was received under T6 conditions as cylindrical rods. The T6 temper designation indicates that this material was solution-treated, and was then artificially aged at $180^{\circ} \mathrm{C}$ for $8 \mathrm{~h}$ to peak conditions. The rods were further aged at $200{ }^{\circ} \mathrm{C}$ for 5,24 , and $48 \mathrm{~h}$ to reach different degrees of overaging. The four aging conditions applied in the presented work are hereafter named as "T6", “T7-5", “T7-24", and "T7-48” in the text, respectively.

Table 1. Chemical composition of the extruded AA6061 alloy (wt. \%).

\begin{tabular}{cccccccc}
\hline Material & $\mathbf{M n}$ & $\mathbf{S i}$ & $\mathbf{C u}$ & $\mathbf{C r}$ & $\mathbf{M g}$ & $\mathbf{F e}$ & $\mathbf{A l}$ \\
\hline 6061 & 0.045 & 0.63 & 0.26 & 0.05 & 0.85 & 0.25 & Balance \\
\hline
\end{tabular}

Sub-sized tensile and fatigue samples were machined with the loading axis parallel to the extrusion direction. The dimensions of samples for the tensile and LCF tests are shown in Figure 1. Prior to testing, the gauge sections of the tensile and fatigue specimens were progressively ground along the loading direction with emery papers up to a grit number of 600 to remove residual stresses and any machining marks. Tensile tests were performed in accordance with the ASTM E8 standard 
in an Instron 8801 servo-hydraulic testing system (Instron, Norwood, MA, USA) at a strain rate of $1 \times 10^{-3} \mathrm{~s}^{-1}$ at room temperature. Strain-controlled (total strain) "pull/push"-type fatigue tests, in accordance with the ASTM: E606 standard, were conducted in air at room temperature with a 25-mm extensometer using a fully computerized Instron 8801 servo-hydraulic testing system operated with the Bluehill LCF3 software (Version 3, Instron, Norwood, MA, USA). The cyclic-deformation test conditions consisted of a zero-mean strain (i.e., a strain ratio of $R_{\varepsilon}=-1$, completely reversed strain cycle) and a constant strain rate of $1 \times 10^{-2} \mathrm{~s}^{-1}$ with a triangular loading waveform. As preferred in the ASTM: E606 standard for continuous cyclic tests, and generally for strain-rate-sensitive materials, a triangular waveform results in a constant strain rate during the course of one cycle. The cyclic frequency was varied depending on the strain amplitude to maintain a fixed strain rate. The cyclic frequency was calculated using the triangular waveform, and it was varied depending on the strain amplitude to maintain a fixed strain rate. LCF tests were performed at different strain amplitudes ranging from $0.2 \%$ to $1.2 \%$. At least two samples were tested at each level of the strain amplitude to confirm the results. At low strain amplitudes (e.g., $0.2 \%$ ), strain-controlled tests were sustained for 10,000 cycles before being converted to load control, with a sine cyclic waveform at a frequency of $50 \mathrm{~Hz}$. The fatigue life was considered as the number of cycles required to completely separate the samples.

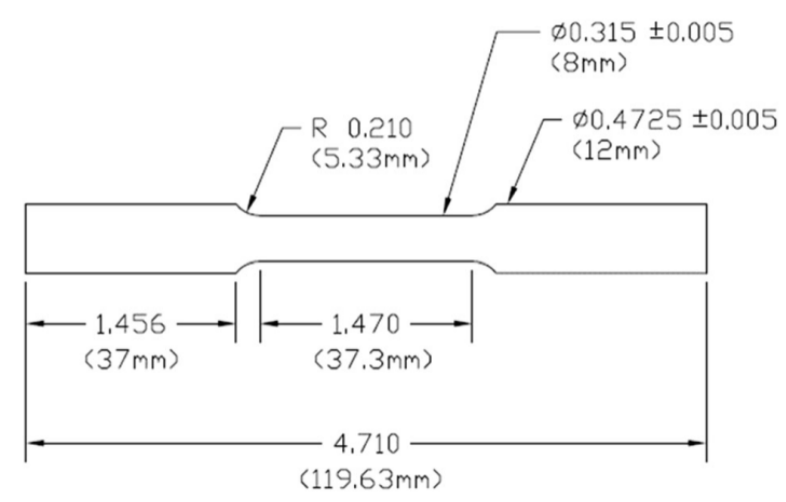

Figure 1. Dimensions of samples for the tensile test and the low-cycle fatigue (LCF) test in the presented work.

The evolution of the microstructure, particularly the intermetallics and grains, were characterized using optical microscopy and scanning electron microscopy (SEM, JSM-6480 LV, JEOL, Tokyo, Japan). Transmission electron microscopy (TEM, JEM-2100, JEOL, Tokyo, Japan) was applied with an operating voltage of $200 \mathrm{kV}$ to observe the $\mathrm{Mg}_{2} \mathrm{Si}$ precipitates under various aging conditions. The TEM samples were prepared by twin-jet electropolishing. After the LCF tests, the fracture surfaces of samples were examined with SEM, with the aim of identifying the various features involved in the fatigue initiation and propagation mechanisms.

\section{Results and Discussion}

\subsection{Microstructure Evolution During Aging Treatment}

Figure 2 shows the typical optical micrographs of the investigated 6061 alloy under T6 and T7-48 conditions. Generally, two types of particles can be found in all four aging conditions: the gray Al-Fe-Si intermetallics and the black undissolved $\mathrm{Mg}_{2} \mathrm{Si}$ particles, both of which are fine due to the extrusion process [18]. No obvious change can be observed in the size and the volume fraction of the two intermetallic particles, as aging at $200^{\circ} \mathrm{C}$ could not cause any remarkable changes in these intermetallic particles [19].

To reveal the grain size and structure, electron back-scattered diffraction (EBSD) mapping was performed for all four aged samples. The EBSD results show that the extruded materials were all fully 
recrystallized with equiaxed grains, and no difference could be found under the four aging conditions. As an example, the EBSD mapping images of T6 and T7-48 are shown in Figure 3. It can be observed that the equiaxed grains are all over the sample section in both aging conditions, with a similar grain size in the range of $60-100 \mu \mathrm{m}$.
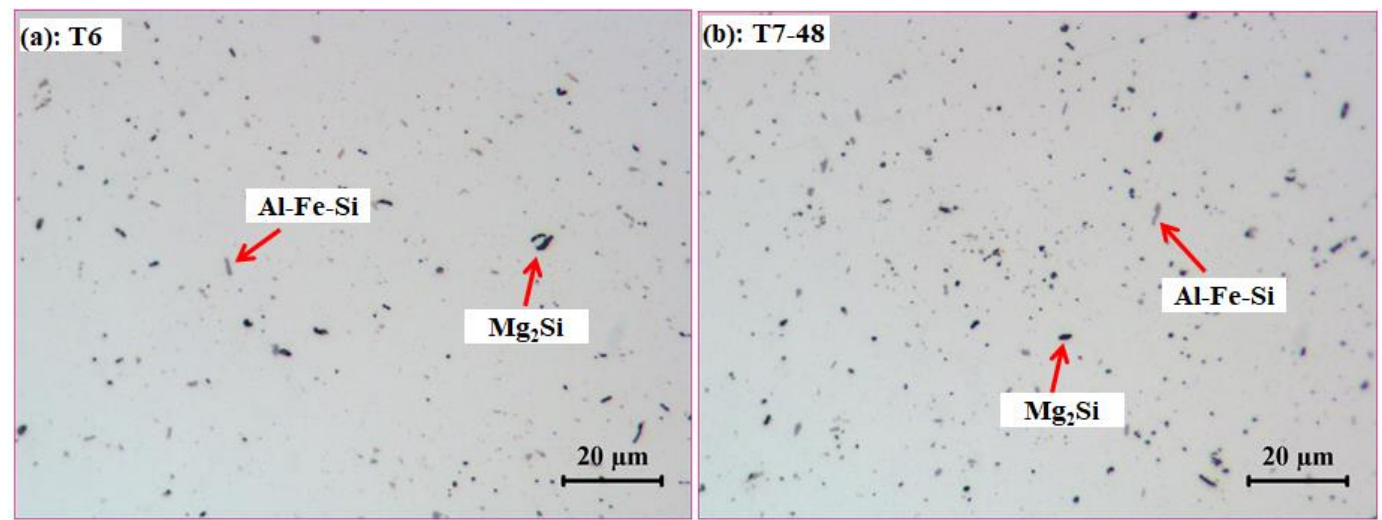

Figure 2. Microstructure of the experimental 6061 alloy under (a) T6 and (b) T6 further aged for $48 \mathrm{~h}$ (T7-48) conditions.
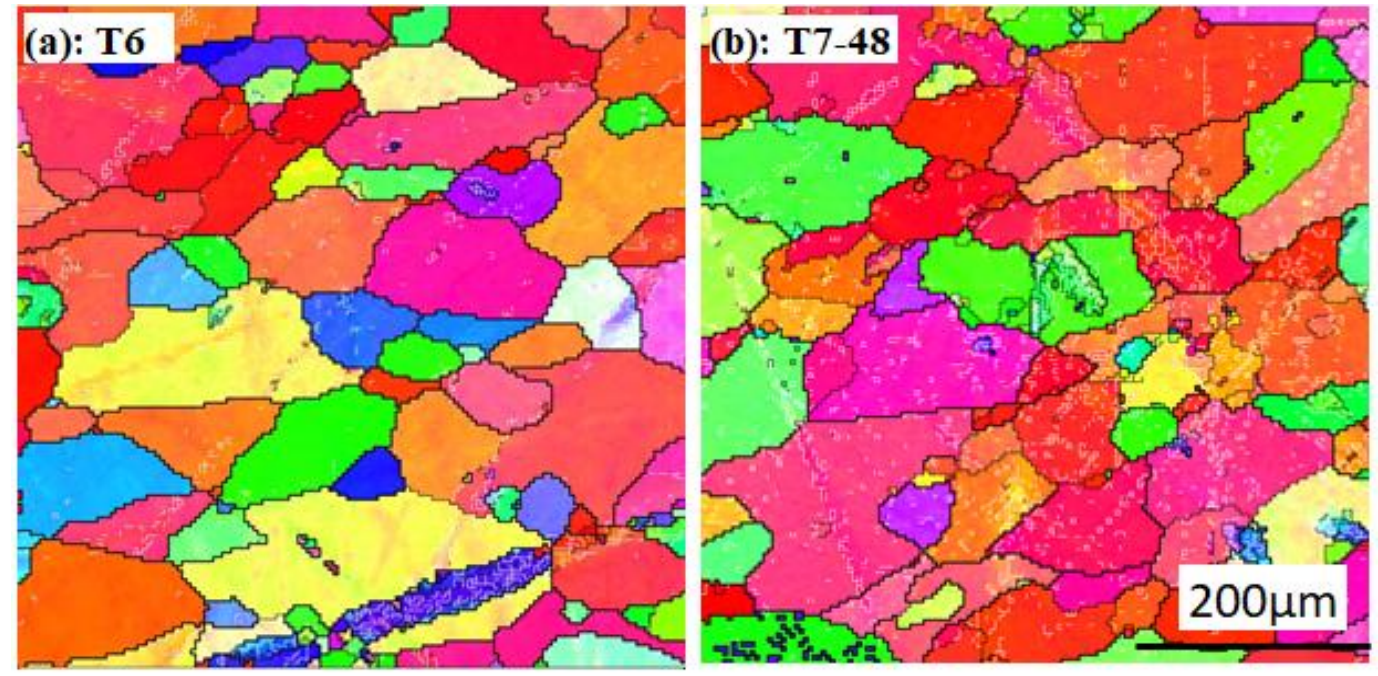

Figure 3. Electron back-scattered diffraction (EBSD) mapping results showing the grain structure under (a) T6 and (b) T7-48 conditions.

Figure 4 shows bright-field TEM images of the precipitates in the aluminum matrix for the four aging conditions. As shown in Figure $4 \mathrm{a}$, the precipitates were very fine with an average length of $60 \mathrm{~nm}$ under T6 conditions. The precipitates under T7-5 conditions were similar to those under T6 conditions in terms of their morphology, but the average length increased to $85 \mathrm{~nm}$ (Figure 4b). However, as the aging time at $200{ }^{\circ} \mathrm{C}$ increased to $24 \mathrm{~h}$ and $48 \mathrm{~h}$, a remarkable increase in the precipitate size can be found in comparison to that under T6 conditions (Figure 4c,d). For instance, the average length of the precipitates reached $220 \mathrm{~nm}$ after $48 \mathrm{~h}$ at $200{ }^{\circ} \mathrm{C}(\mathrm{T} 7-48$, Figure $4 \mathrm{~d})$. In addition, the number density (volume fraction) of precipitates with longer aging times was much lower than that under T6 conditions. The precipitation microstructure during aging for 6061 alloys ( $\mathrm{Mg}_{2} \mathrm{Si}$ precipitates) is well known in the literature [3,19-21]. Comparing the morphology and length of the precipitates (Figure 4) to those in the literature, the dominant precipitates under the T6 and T7-5 conditions were most likely the semi-coherent $\beta^{\prime \prime}-\mathrm{Mg}_{2} \mathrm{Si}$, which is reported to be still shearable [17], while the major precipitates under the T7-24 and T7-48 conditions were $\beta^{\prime}-\mathrm{Mg}_{2} \mathrm{Si}$, which is non-coherent and non-shearable [21]. 

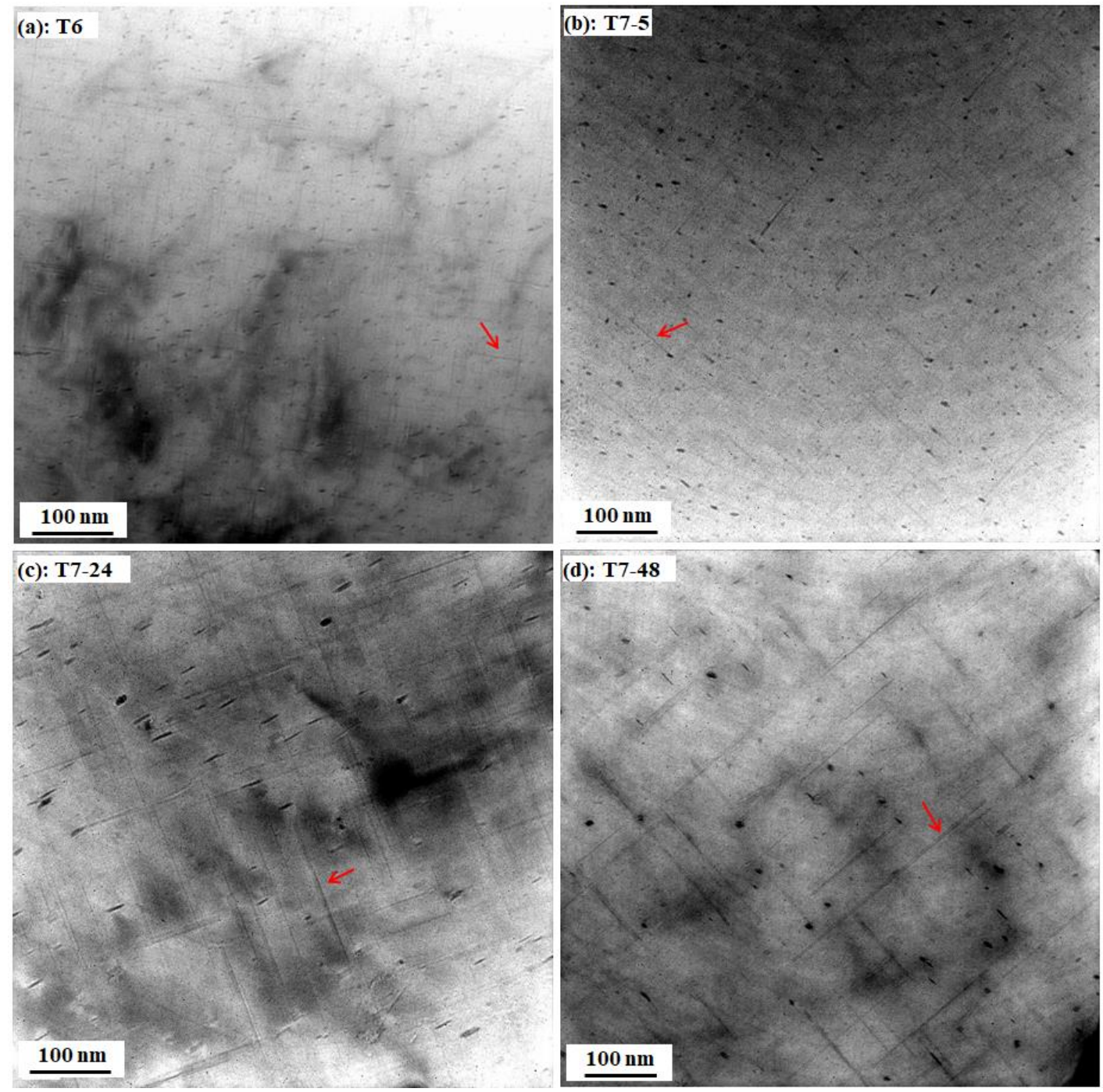

Figure 4. Transmission electron microscopy (TEM) bright-field images of the precipitates under various aging conditions. (a)T6; (b)T7-5; (c) T7-24; and (d)T7-48.

\subsection{Monotonic Tensile Properties under Various Aging Conditions}

Typical tensile properties of the investigated 6061 alloy obtained under various aging conditions are listed in Table 2. As seen from Table 2, both the yield strength (YS) and ultimate tensile strengths (UTS) decreased, whereas the elongation increased, with increasing aging time. Only small changes in the strength were observed between the T6 and T7- 5 conditions, and between the T7-24 and T7-48 conditions. However, a large difference in strength occurred between these two groups. For instance, YS only decreased by $11 \mathrm{MPa}$ between T6 (286 MPa) and T7-5 (275 MPa), but YS dropped by $67 \mathrm{MPa}$ from T7-5 (275 MPa) to T7-24 (208 MPa). The evolution of the mechanical properties was highly related to the precipitates under various aging conditions. As shown in Figure 4, the size of precipitates increased and the number density of precipitates decreased with aging time, leading to decreasing strength according to the Orowan strengthening mechanism [22]. Corresponding to the strength change, it can be observed that the precipitate sizes were similar between T6 and T7-5 (in the range of 60-90 nm), and between T7-24 and T7-48 (in the range of 200-220 nm). However, the morphology and type of the precipitates in these two groups changed significantly, whereby $\beta^{\prime \prime}-\mathrm{Mg}_{2} \mathrm{Si}$ precipitates of fine size were dominant in $\mathrm{T} 6$ and T7-5, while $\beta^{\prime}-\mathrm{Mg}_{2} \mathrm{Si}$ precipitates of coarse size were prevalent in T7-24 and T7-48, which explains the sharp drop in strength from T6 to T7-24 and T7-48. 
Table 2. Monotonic material properties under various aging conditions (T6, and T6 further aged for 5 (T7-5), 24 (T7-24), and 48 (T7-48) hours).

\begin{tabular}{ccccccc}
\hline Condition & $\begin{array}{c}\text { Yield } \\
\text { Strength YS } \\
\text { (MPa) }\end{array}$ & $\begin{array}{c}\text { Ultimate } \\
\text { Strength UTS } \\
\text { (MPa) }\end{array}$ & UTS/YS & $\begin{array}{c}\text { Elongation } \\
\text { El (\%) }\end{array}$ & $\begin{array}{c}\text { Strain-Hardening } \\
\text { Exponent }\end{array}$ & $\begin{array}{c}\text { K/MPa, Monotonic } \\
\text { Strength } \\
\text { Coefficient }\end{array}$ \\
\hline T6 & $286(5.2) *$ & $319(6.7)$ & 1.12 & $14.6(2.3)$ & 0.10 & 439 \\
T7-5 & $275(4.8)$ & $305(6.1)$ & 1.11 & $15.5(1.5)$ & 0.10 & 424 \\
T7-24 & $208(4.1)$ & $244(5.8)$ & 1.17 & $17.9(2.3)$ & 0.12 & 365 \\
T7-48 & $188(4.5)$ & $228(5.2)$ & 1.21 & $19.6(2.8)$ & 0.14 & 356 \\
6061-T6 [2] & 300 & 338 & 1.13 & 13 & N/A & 480 \\
\hline
\end{tabular}

It is also interesting to note that the strain-hardening exponent $(n)$ increased and the strength coefficient $(K)$ decreased with increasing aging time. Similar results were reported for the AA6061-T6 alloy by Adnan et al. [2], and for the AA2024-T6 and AA7020-T6 alloys by Haji [6]. It was reported that the strain-hardening exponent has a major influence on the forming operation, which controls the amount of uniform plastic strain in the material before strain localization or necking [23]. Therefore, with an increasing strain-hardening exponent, more plastic deformation occurs after the yield point, but before the necking; consequently, the ductility of materials is improved, exemplified by the elongation shown in Table 2. On the other hand, the strength coefficient $(K)$ represents the real stress when the real strain is 1, and it is greatly correlated to the treatment conditions of a material [24]. In the presented work, the real stress decreased owing to the coarsening of precipitates with increasing aging time and temperature, resulting in a decreasing $K$ value. Compared to the mechanical properties under the same T6 conditions in the literature [2], the experimental alloy had similar mechanical properties.

\subsection{LCF Fatigue Behavior under Various Aging Conditions}

\subsubsection{Hysteresis Loops}

In order to show the LCF behavior trends of the investigated 6061 alloy, the strain amplitudes of $0.4 \%, 0.8 \%$, and $1.2 \%$ were selected to represent the LCF results at low, middle, and high strain amplitudes. The hysteresis loops of the first cycle and the mid-life stable cycle under various aging conditions are illustrated in Figure 5. Nearly symmetrical hysteresis loops could be observed under all aging conditions at all strain amplitudes, which were similar to those of face-centered cubic (FCC) metals (e.g., $\mathrm{Al}, \mathrm{Cu}$, and $\mathrm{Ni}$ ) as a result of the dislocation-slip-dominated deformation in most materials [25].

However, despite the similarity, there were differences under various aging conditions. Firstly, the shape of loops with longer aging time at T7 became inflected, especially at higher strain amplitudes. As indicated by the arrows in Figure 5a,c,e, the loops were noticeably flattened after T7-48, which was also reported in the work of Hidayetoglu et al. [8]. The inflection was only present during the first few cycles, and disappeared gradually as cycling proceeded. As shown in Figure $5 b, d, f$, no obvious inflection could be observed during the mid-life cycle. The inflection for the first few cycles with longer aging time can be attributed to the different precipitates formed during the aging treatment [8]. For the T6 and T7-5 conditions, as shown in Figure 4, the precipitates could be sheared [17] during the "to-and-fro" motion of dislocations during LCF, leading to the "normal" hysteresis loop without inflection. Nevertheless, the precipitates were non-shearable under the T7-24 and T7-48 conditions. These non-shearable precipitates pinned the movement of dislocations by forming a dislocation loop, resulting in a population of mobile dislocations around each precipitate when the forward stress was first applied. These dislocation loops can provide a limited amount of strain in the reverse direction at relatively low stress. Only when they are exhausted will the reverse stress increase to a value approaching that of the forward stress in order to continue reverse straining, thereby causing the inflection in the first few cycles. With increasing cycles, the contribution of dislocation loops diminishes, and then, the inflection disappears [8]. 

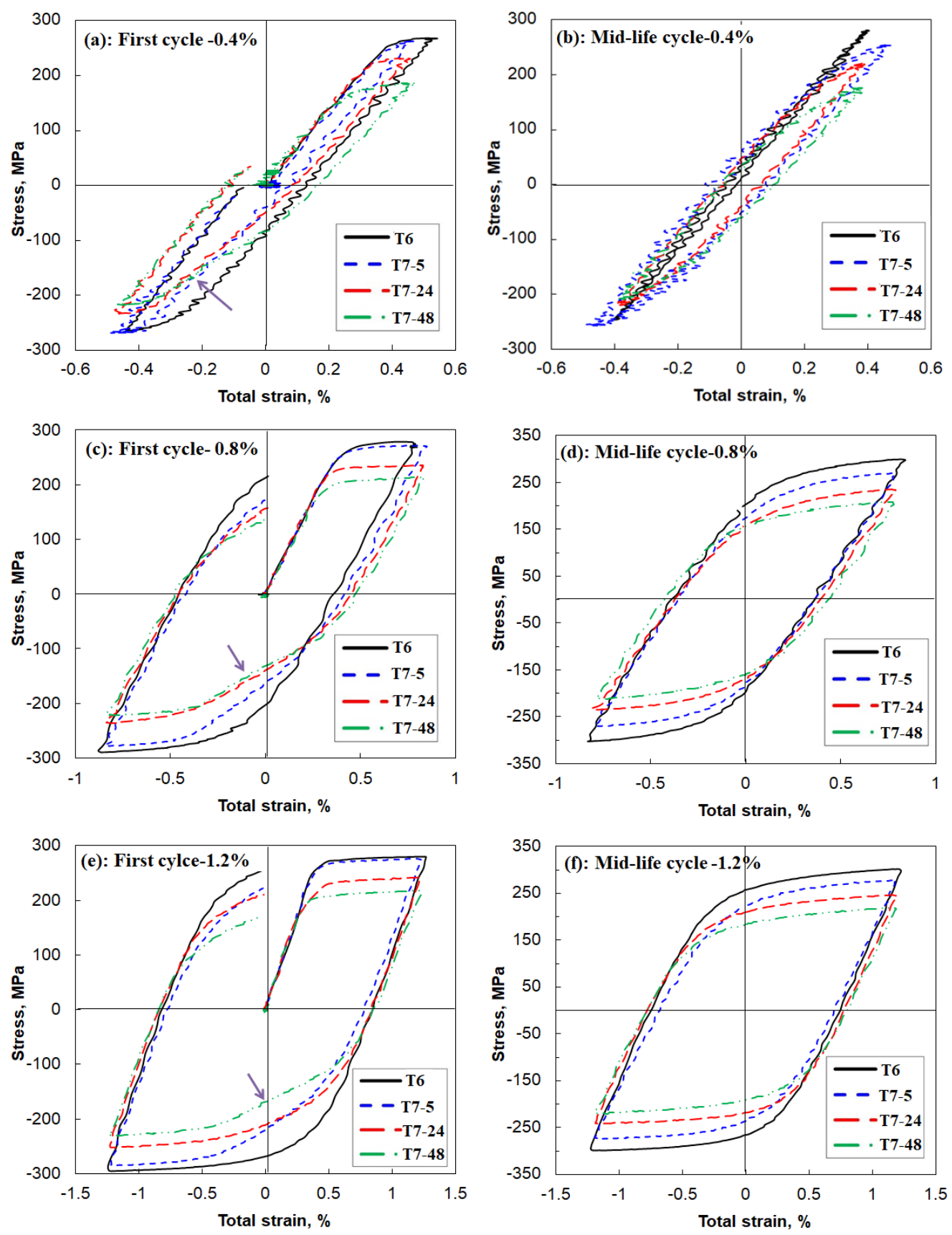

Figure 5. First and mid-life cycle hysteresis loops under various aging conditions at given strain amplitudes of (a,b) $0.4 \%$, (c,d) $0.8 \%$, and (e,f) $1.2 \%$.

Secondly, the maximum/minimum peak stresses decreased with increasing T7 aging time at all strain amplitudes. In the first cycle, the maximum/minimum peak stresses were similar between T6 and T7-5 to those between the T7-24 and T7-48 conditions, but they decreased from T6/T7-5 to T7-24/T7-48, which was similar to the evolution of the monotonic mechanical properties (Table 2). In the mid-life cycle, the difference in peak stresses between each aging condition became larger, indicating the varying cyclic stress and strain response under various aging conditions. Table 3 lists the differences in peak stresses and plastic strain between T6 and various T7 conditions during the first and mid-life cycles. It was also noted that the plastic strain generally increased with increasing aging time. Taking the strain amplitude of $0.8 \%$ as an example, as shown in Table 3, the difference in maximum peak stress between $\mathrm{T} 6$ and T7-5 was $14 \mathrm{MPa}$, but it increased between T6 and T7-24 
(43 MPa) during the first cycle. During the mid-life cycle, the differences became even larger, e.g., it was $19 \mathrm{MPa}$ between T6 and T7-5, and $53 \mathrm{MPa}$ between T6 and T7-24. For the changes in plastic strain relative to T6, it increased from 0.08 at T7-5 to 0.10 at T7-24, and further increased to 0.13 at T7-48 during the first cycle, whereas it increased from 0.05 to 0.07 , and further to 0.11 during the mid-life cycle. The decrease in cyclic stresses with increasing T7 aging time can be attributed to the transformation of precipitates, as shown in Figure 4, whereas the changes with cycles, such as the differences in peak stresses and plastic strain during the first cycle and mid-life cycle were probably due to their different cyclic responses.

Table 3. Differences in peak stresses and plastic strain between T6 and various T7 conditions during the first and mid-life cycles.

\begin{tabular}{|c|c|c|c|c|c|c|c|}
\hline \multirow{2}{*}{$\begin{array}{c}\text { Strain } \\
\text { Amplitude (\%) }\end{array}$} & \multirow[b]{2}{*}{ Condition } & \multicolumn{3}{|c|}{ First Cycle } & \multicolumn{3}{|c|}{ Mid-Life Cycle } \\
\hline & & $\begin{array}{l}\Delta \sigma_{\max } \\
(\mathrm{MPa})\end{array}$ & $\begin{array}{l}\Delta \sigma_{\min } \\
(\mathrm{MPa})\end{array}$ & $\Delta \varepsilon_{p}(\%)$ & $\begin{array}{l}\Delta \sigma_{\max } \\
(\mathrm{MPa})\end{array}$ & $\begin{array}{l}\Delta \sigma_{\min } \\
(\mathrm{MPa})\end{array}$ & $\Delta \varepsilon_{p}(\%)$ \\
\hline \multirow{3}{*}{0.4} & T7-5 & -8.91 & 0.67 & 0.26 & -21.27 & -12.58 & 0.10 \\
\hline & T7-24 & -36.97 & 30.03 & -0.19 & -61.39 & 27.60 & 0.09 \\
\hline & $\mathrm{T} 7-48$ & -65.82 & 50.60 & 0.12 & -83.76 & 46.48 & 0.11 \\
\hline \multirow{3}{*}{0.8} & T7-5 & -14.15 & 18.70 & 0.08 & -32.39 & 34.79 & 0.05 \\
\hline & $\mathrm{T} 7-24$ & -42.67 & 53.12 & 0.10 & -64.08 & 67.48 & 0.07 \\
\hline & $\mathrm{T} 7-48$ & -50.68 & 66.07 & 0.13 & -90.90 & 90.84 & 0.11 \\
\hline \multirow{3}{*}{1.2} & T7-5 & -2.14 & 9.79 & -0.10 & -21.54 & 21.93 & -0.11 \\
\hline & $\mathrm{T} 7-24$ & -40.87 & 43.40 & -0.01 & -56.92 & 59.71 & 0.05 \\
\hline & $\mathrm{T} 7-48$ & -63.02 & 65.37 & 0.04 & -83.15 & 79.09 & 0.09 \\
\hline
\end{tabular}

Figure 6 presents the stable stress-strain hysteresis loops in the mid-life cycle at various strain amplitudes, plotted in relative coordinates corresponding to a translation of the loop ascending branches in such a way that their tips coincided at the positions of the load reversal in compression. T6 and T7-48 were selected to represent the two extreme conditions. The difference between the two conditions is obvious in terms of Masing behavior. Masing behavior is defined by comparing the shapes of hysteresis loops with the cyclic stress-strain curves drawn in the mode mentioned above. If the shape of the loop matches with the cyclic stress-strain curve, Masing behavior is considered to apply [26]. As shown in Figure 6a, the ascending branches of the loops obtained for T6 were almost coincident, exhibiting nearly ideal Masing behavior [27]. On the contrary, the alloy under T7-48 conditions clearly deviated from Masing behavior (Figure 6b), in which the curves were separated with increasing total strain amplitude, especially in the positions indicated with a blue circle.
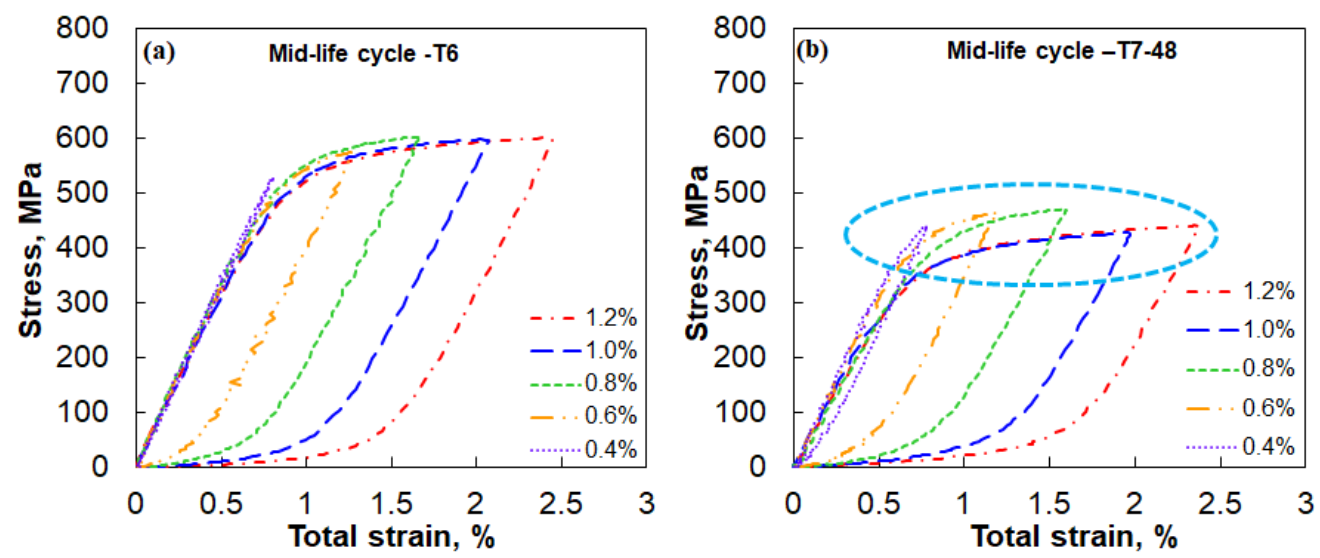

Figure 6. Superimposed stress-strain hysteresis loops with matched lower tips in the mid-life cycle at various total strain amplitudes: (a) T6 and (b) T7-48 conditions. 
Masing behavior is reported to be present if the dislocation-dislocation interaction plays a more important role than the dislocation-precipitate interaction during the plastic deformation of any multiphase material [27]. Therefore, it can be inferred that the interaction between dislocations was favored under T6 conditions, with Masing behavior owing to the shearable precipitates. However, the dislocation-precipitate interaction played a major role under T7-48 conditions, owing to the non-shearable precipitates after longer T7 aging times.

\subsubsection{Cyclic Stress and Strain Responses}

The evolution of stress amplitudes with respect to the number of cycles at various strain amplitudes $(0.4 \%, 0.8 \%$, and $1.2 \%)$ is shown in Figure 7 , under various aging conditions, with a semi-logarithmic scale along the $X$-axis.
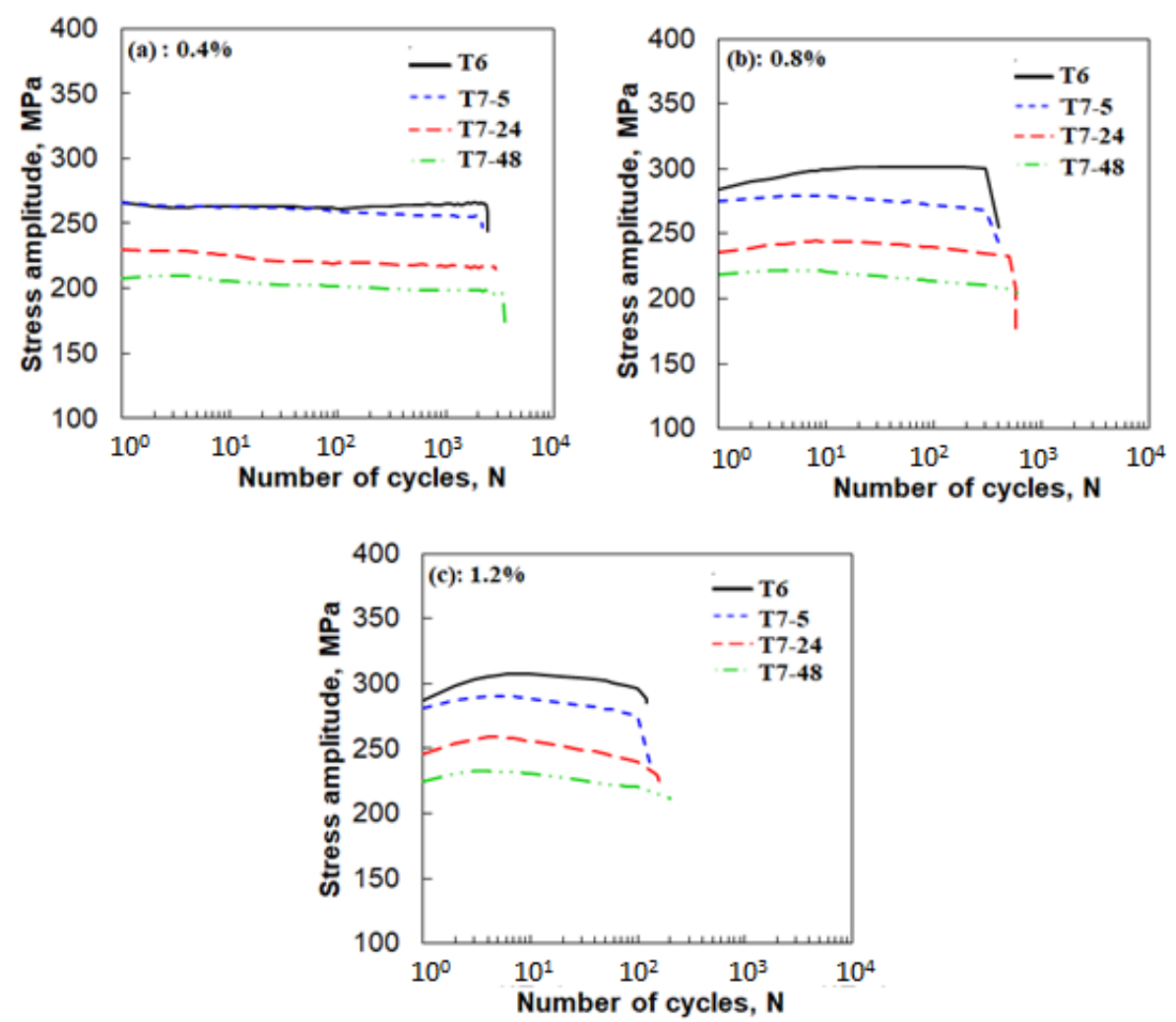

Figure 7. Stress amplitude vs. the number of cycles under various aging conditions tested at various strain amplitudes of (a) $0.4 \%$, (b) $0.8 \%$, and (c) $1.2 \%$.

It was observed from Figure 7 that the stress amplitude augmented, whereas the fatigue life decreased with increasing strain amplitude. It can be found that the stress amplitudes of T6 and T7-5 were always higher than those of T7-24 and T7-48 at all strain amplitudes tested. In addition, a similar cyclic response was observed for all aging conditions, although it was different at applied strain amplitudes. At the low strain amplitude of $0.4 \%$ (Figure $7 \mathrm{a}$ ), cyclic stabilization occurred under all aging conditions. At the middle strain amplitude of $0.8 \%$ (Figure $7 \mathrm{~b}$ ), initial hardening can be observed during the first few cycles ( 10), followed by stabilization from T6 to T7-48. When the higher strain amplitude was applied (1.2\% in Figure $7 \mathrm{c})$, hardening appeared during the first few cycles, followed by softening until failure for all aging conditions. Because the hardening only happened during the first few cycles, the cyclic response for all aging conditions can be described as stabilization at lower stain amplitudes, and softening at higher strain amplitudes. However, minor differences can be found in the hardening or softening rates under various aging conditions. As shown in Figure $7 \mathrm{c}$, the hardening rates in the first few cycles were higher, with lower softening rates in the following cycles under the 
T6/T7-5 conditions than under the T7-24/T7-48 conditions, which explains the increasing difference in stress and the decreasing difference in plastic strain between the first and mid-life cycles, as shown in Table 3.

In the LCF tests, the plastic strain amplitude was considered as a physical quantity that resulted in several damaging processes, and it influenced the internal microstructure, which was closely related to the strain resistance, and eventually, the fatigue life [28]. The variation in plastic strain amplitude $\left(\Delta \varepsilon_{\mathrm{p}} / 2\right)$ during cyclic deformation at various strain amplitudes $(0.4 \%, 0.8 \%$, and $1.2 \%)$ under various aging conditions is shown in Figure 8, which corresponded well with the change in stress amplitude during cyclic deformation, as shown in Figure 7. As shown in Figure 8, the plastic strain amplitude also increased with total strain amplitude. When the total strain amplitude was low $(\sim 0.4 \%$ in Figure $8 \mathrm{a})$, cyclic stabilization was observed. With increasing total strain amplitude $(0.8 \%$ in Figure $8 b$, and $1.2 \%$ in Figure 8c), plastic strain decreased with cycles.

It is well accepted that the cyclic hardening or softening during LCF tests is highly dependent on the ratio of $\sigma_{\text {UTS }}$ to $\sigma_{Y S}$, whereby cyclic hardening dominates when the ratio is higher than 1.4, and cyclic softening is expected to occur when the value is lower than 1.2 [29]. As shown in Table 2, the values of the $\sigma_{\text {UTS }}$-to- $\sigma_{Y S}$ ratio for all four aging conditions were in the range of 1.1-1.2, and therefore, stabilization or softening was the dominant cyclic response for all aging conditions. The hardening during the first few cycles was probably due to the classical dislocation-dislocation interactions $[30,31]$, whereas the twisting, dissolution, and slip penetration of precipitates were the principal reasons for the softening [32].

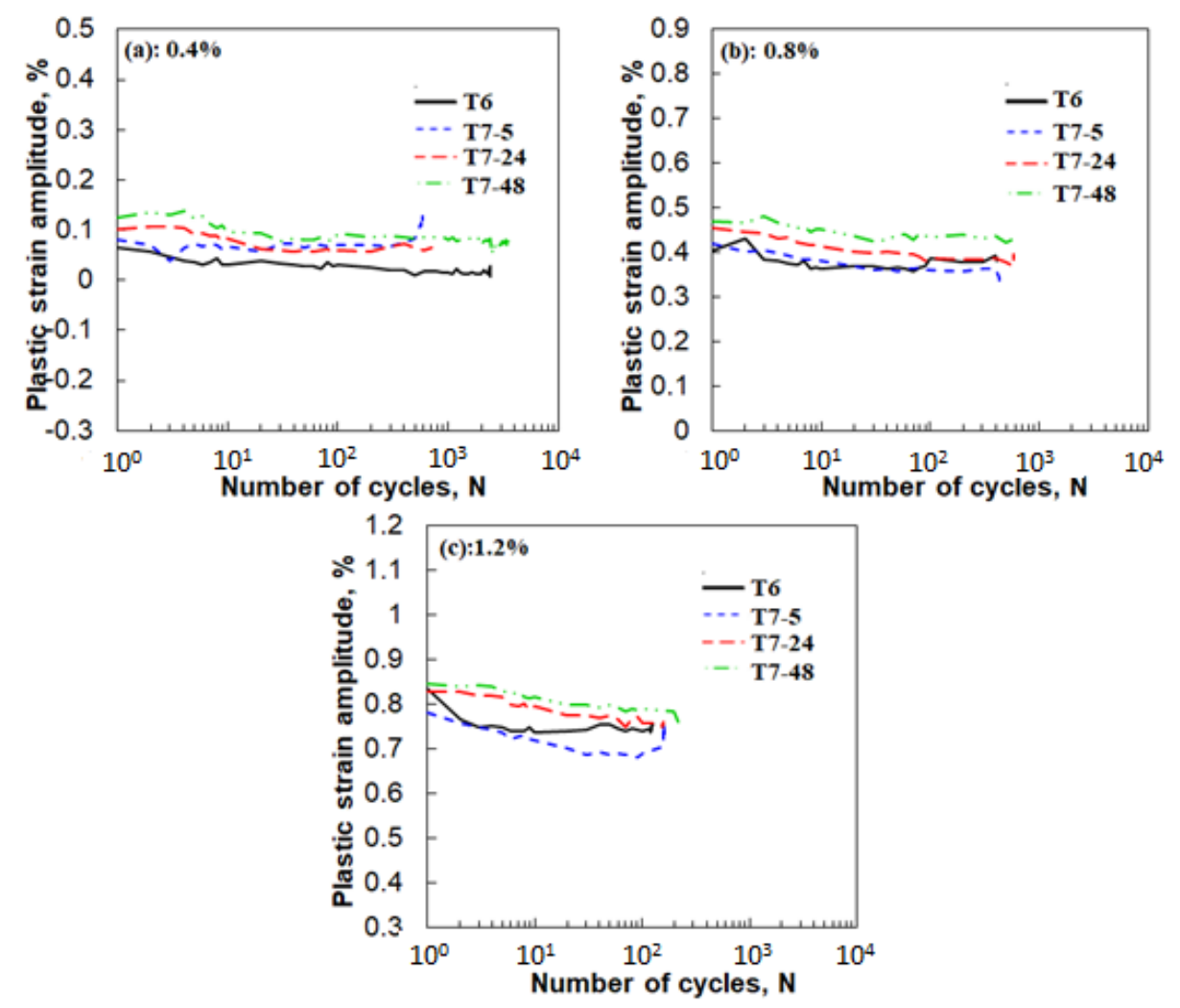

Figure 8. Plastic strain amplitude vs. the number of cycles under various aging conditions tested at various strain amplitudes of (a) $0.4 \%$, (b) $0.8 \%$, and (c) $1.2 \%$.

\subsubsection{Fatigue Life and Fatigue Fracture}

Figure 9 displays the total strain amplitude $\left(\Delta \varepsilon_{t} / 2\right)$ as a function of the number of cycles to failure $\left(N_{f}\right.$, i.e., the fatigue life) for the investigated 6061 alloy under various aging conditions, in comparison 
with the data reported in the literature [1]. The run-out data points are marked by arrows pointing horizontally at or over $10^{4}$ cycles. Overall, the investigated 6061 alloy showed a trend of increasing fatigue life with decreasing strain amplitude, and it also showed an improved fatigue life compared to the data reported in the literature [1]. In general, the fatigue life increased with increasing T7 aging time. It is apparent that the fatigue life under the T7-24/T7-48 conditions was longer than that for T6/T7-5.

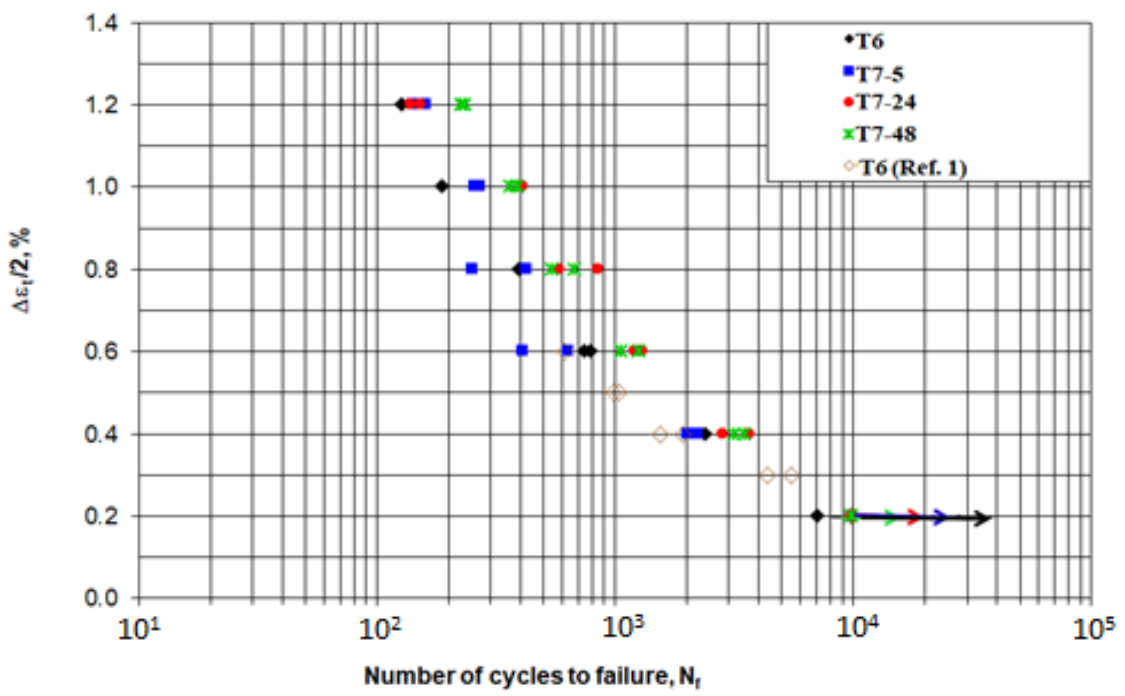

Figure 9. Total strain amplitude vs. number of cycles to failure under various aging conditions.

A similar trend was reported in the literature [33], in which the fatigue life of the A356 alloy was greatly improved by prolonging the aging time, which is explained by the relationship between the fatigue life and yield strength. If the material has a low yield strength due to overaging, the stress concentration generated within the uneven area of the material is easily relaxed by the plastic deformation of the part; thus, the initiation of fatigue crack is delayed, and it survives for a longer period. The relationship between the maximum size of the plastic deformation zone surrounding the fatigue-crack tip and the yield strength of the material can be described as follows [33]:

$$
r_{p}=0.11\left(\frac{K_{\max }^{\mathrm{tr}}}{\sigma_{y}}\right)^{2},
$$

where $r_{p}$ is the size of the plastic zone, $K_{\max }^{\mathrm{tr}}$ is the transition-maximum applied stress-intensity factor, and $\sigma_{y}$ is the yield strength. Based on Equation (1), the low yield strength can increase the size of the local plastic deformation zone, thereby promoting the crack closure induced by the high plasticity, and subsequently, increasing the crack growth resistance [33]. In addition, the larger plastic deformation zone can also increase the resistance of the intracellular matrix to dislocations, causing these dislocations to be unable to move close to the unit cell or grain boundary to interact with eutectic particles; therefore, it reduces the propagation rate of fatigue crack, and further improves the fatigue properties of the alloy. Comparing the T6/T7-5 to T7-24/T7-48 conditions for the investigated 6061 alloy, the lower yield strength with prolonged aging time was likely the main reason for the longer fatigue life.

Figure 10 shows fracture surfaces of the investigated alloy under the T6 and T7-48 conditions at a total strain amplitude of $0.4 \%$ and $1.0 \%$, including fatigue-crack initiation, propagation, and final fast-fracture regions (as indicated by dashed yellow and red lines). 

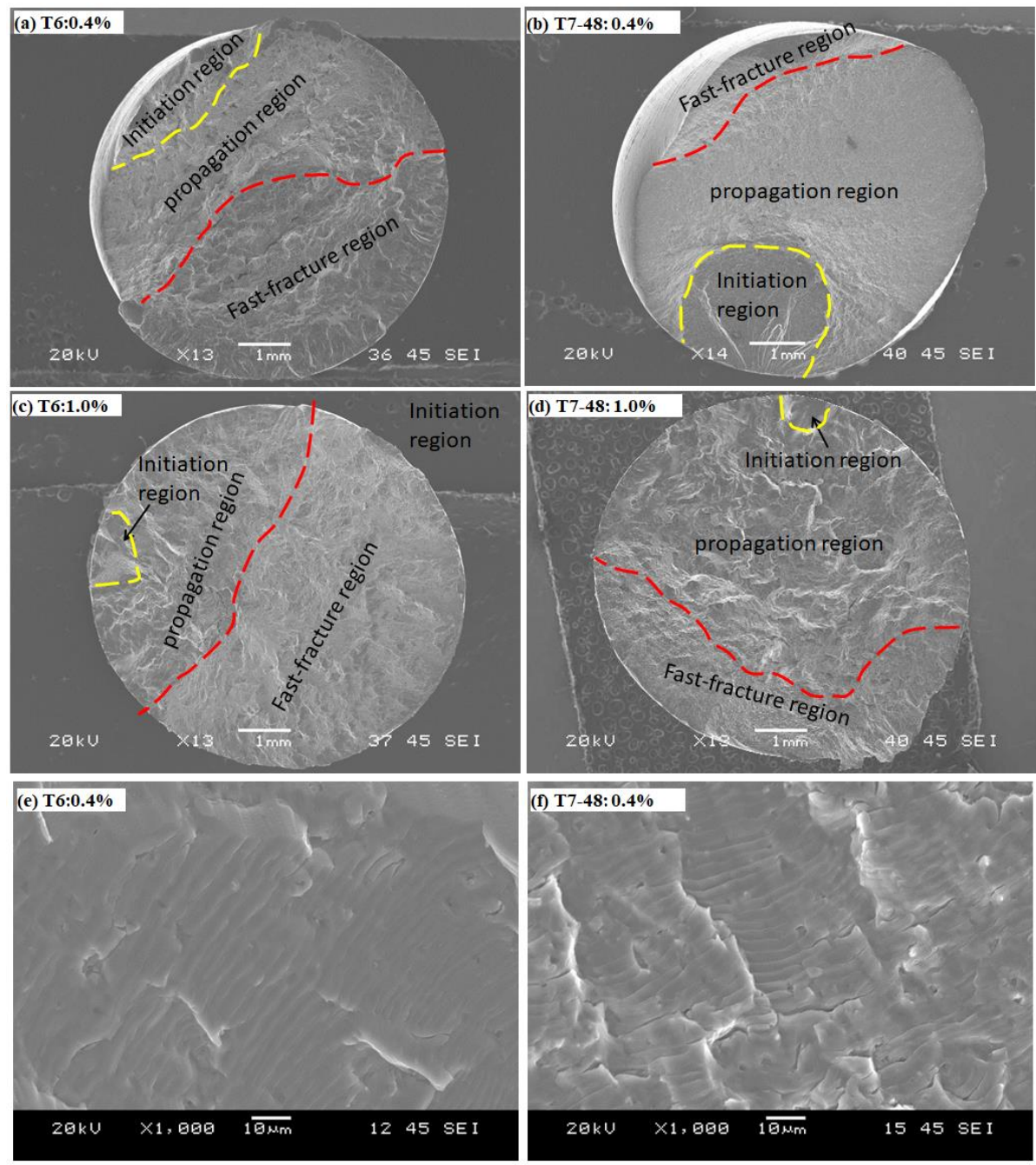

Figure 10. Fatigue fracture surfaces at strain amplitudes of $0.4 \%$ and $1.0 \%$ under $(\mathbf{a}, \mathbf{c}, \mathbf{e}) \mathrm{T} 6$ and $(\mathbf{b}, \mathbf{d}, \mathbf{f})$ T7-48 conditions.

It can be seen in Figure 10 that the fatigue crack initiated essentially from the specimen surface, caused by the near-surface defects, such as porosities and brittle particles [34]. The greatest differences between these two conditions (T6 and T7-48) were in the areas of the crack propagation. As shown in Figure 10b,d, the area of the crack propagation under the T7-48 conditions was much larger than that under the T6 conditions (Figure 10a,c) at both low $(0.4 \%)$ and high $(1.0 \%)$ strain amplitude, which was corroborated by the larger plastic deformation (Figure 6) and longer fatigue life of the T7-48 sample (Figure 9) compared to the T6 sample. Fatigue striations on the fatigue fracture surface under both conditions were also observed, especially at lower stain amplitudes, such as $0.4 \%$, as shown in Figure 10e,f. The presence of fatigue-striation marks is characteristic of the crack-propagation regime in ductile materials [17], such as the investigated 6061 aluminum alloys. It was observed that the spacing of fatigue striations in the T6 sample was somewhat larger than that in the T7-48 sample, indicating a faster crack-propagation rate. This explains the shorter fatigue life in the T6 sample, combined with a smaller propagation region.

\subsubsection{Assessment of Fatigue Parameters}

Based on the LCF results (Figures 6 and 8), the fatigue parameters were calculated to assess the fatigue life of the investigated 6061 aluminum alloy under various conditions. The total strain 
amplitude could be expressed as two parts: the plastic and elastic strain amplitudes, according to the Coffin-Manson and Basquin relationships [35], i.e.,

$$
\frac{\Delta \varepsilon_{t}}{2}=\frac{\Delta \varepsilon_{p}}{2}+\frac{\Delta \varepsilon_{e}}{2}=\varepsilon_{f^{\prime}}\left(2 N_{f}\right)^{c}+\frac{\sigma_{f}^{\prime}\left(2 N_{f}\right)^{b}}{E},
$$

where $E$ is the Young's modulus (for the presented alloy, the average value obtained during fatigue testing was $\sim 68 \mathrm{GPa}$ ), $N_{f}$ is the fatigue life or the number of cycles to failure, $\sigma_{f}^{\prime}$ is the fatigue strength coefficient, $b$ is the fatigue strength exponent, $\varepsilon_{f}^{\prime}$ is the fatigue ductility coefficient, and $c$ is the fatigue ductility exponent. In addition, cyclic deformation behavior is normally considered to be related to the portion of plastic strain amplitude, and is independent of the elastic strain amplitude, which can be expressed by the following equation [36]:

$$
\frac{\Delta \sigma}{2}=K^{\prime}\left(\frac{\Delta \varepsilon_{p}}{2}\right)^{n^{\prime}}
$$

where $\frac{\Delta \sigma}{2}$ is the mid-life stress amplitude, $\frac{\Delta \varepsilon_{p}}{2}$ is the mid-life plastic strain amplitude, $n^{\prime}$ is the cyclic strain-hardening exponent, and $K^{\prime}$ is the cyclic strength coefficient. The estimated LCF parameters based on Equations (2) and (3), and on the LCF results are presented in Table 4, and are compared with the data reported in the literature for extruded 6061-T6 alloys [1,9]. To ensure that the cyclic stabilization, often called cyclic saturation, already occurred, the stress and strain values of the mid-life cycle were used for the calculations.

As shown in Table 4, it can be seen that the estimated fatigue parameters were well within the range of other extruded 6061 alloys reported in the literature [1,9]. The T6 alloy had the highest $\sigma_{f}^{\prime}$ and $b$ values, but the lowest $\varepsilon_{f}^{\prime}$ and $c$ values of all the examined conditions. This indicates that alloys with higher $\sigma_{f}^{\prime}$ and $b$ values have higher strength, whereas those with higher $\varepsilon_{f}^{\prime}$ and $c$ values have higher ductility [2], which also coincides with the explanation for the longer plastic deformation for the T7 aged alloys (Figure 5). It was observed that the value of the cyclic strain-hardening exponent, $n^{\prime}$, of the T6 alloy was lower than that of the alloys after T7 aging, such as T7-24 and T7-48. It was also reported in the work of Nandy et al. [17] that the cyclic strain-hardening exponent increased from under-aged to peak-aged conditions, and further increased to over-aged conditions. In addition, the values of $n^{\prime}$ in Table 4 during cyclic deformation were higher than its monotonic strain-hardening values $n$ in Table 2, which directly reflects a higher cyclic stress than monotonic tensile stress at the same strain for all conditions tested. Moreover, both the cyclic strength coefficient, $K^{\prime}$, and fatigue strength coefficient, $\sigma_{f}^{\prime}$, decreased with increasing T7 aging time, leading to the lowest stress amplitude (Figure 5 and Table 3 ) in the T7-48 alloy. It is worth mentioning that the fatigue ductility coefficient, $\varepsilon_{f}^{\prime}$, was found to increase with increasing T7 aging time, indicating a higher plastic strain with longer aging time, and therefore, the longer fatigue life of the alloy under the T7-24 and T7-48 conditions compared to that under the T6 conditions.

Table 4. Low-cycle fatigue (LCF) parameters estimated for 6061 aluminum alloys under various conditions.

\begin{tabular}{ccccccc}
\hline Low-Cycle Fatigue Parameters & T6 & T7-5 & T7-24 & T7-48 & T6 [1] & T6 [8] \\
\hline Cyclic strain-hardening exponent, $n^{\prime}$ & 0.14 & 0.12 & 0.15 & 0.18 & 0.078 & 0.24 \\
Cyclic strength coefficient, $K^{\prime}(\mathrm{MPa})$ & 636 & 621 & 552 & 478 & 268 & 372 \\
Fatigue strength coefficient, $\sigma_{f}^{\prime}(\mathrm{MPa})$ & 872 & 613 & 602 & 458 & 705 & 593 \\
Fatigue strength exponent, $b$ & -0.087 & -0.110 & -0.110 & -0.214 & -0.11 & -0.093 \\
Fatigue ductility coefficient, $\varepsilon_{f}^{\prime}$ & 0.70 & 0.90 & 1.80 & 4.49 & 2.40 & 5.39 \\
Fatigue ductility exponent, $c$ & -1.10 & -0.87 & -0.80 & -0.79 & -0.98 & -1.10 \\
\hline
\end{tabular}




\section{Conclusions}

Strain-controlled low-cycle fatigue tests were conducted on an extruded AA6061 aluminum alloy at varying strain amplitudes to determine the effect of overaging on the cyclic deformation behavior. The following conclusions could be drawn:

(1) During the T7 aging treatment at $200{ }^{\circ} \mathrm{C}$, no remarkable changes in the microstructure (Al-Fe-Si and $\mathrm{Mg}_{2} \mathrm{Si}$ intermetallics, and $\alpha$-Al grain size) could be observed with increasing aging time. However, the size of precipitates increased from $60 \mathrm{~nm}$ under the T6 conditions to $220 \mathrm{~nm}$ after aging $48 \mathrm{~h}$ at $200{ }^{\circ} \mathrm{C}$, leading to a decrease in the monotonic tensile strength.

(2) The hysteresis loops of the first cycle after a long T7 aging time were moderately inflected compared to those under the T6 conditions, whereas nearly symmetrical loops were present during the mid-life cycle under all conditions tested. The peak stresses decreased and the plastic strain increased with increasing T7 aging time. Nearly ideal Masing behavior was exhibited under the T6 conditions, whereas it was lost under the overaging conditions.

(3) Similar cyclic stress responses were found under all tested conditions: cyclic stabilization was present at low strain amplitudes $(0.2-0.4 \%)$, whereas cyclic softening with initial hardening during the first few cycles occurred at middle-to-high strain amplitudes (0.6-1.2\%). The softening rate increased gradually with increasing $\mathrm{T} 7$ aging time.

(4) Compared to the T6 conditions, the fatigue life increased with increasing T7 aging time. The estimated fatigue parameters indicated that the fatigue ductility coefficient increased and the fatigue strength coefficient decreased with increasing T7 aging time.

Author Contributions: K.L., F.A.M. and X.G.C. conceived and designed the experiments; F.A.M. and K.L. performed the experiments; F.A.M. analyzed the data; F.A.M. and K.L. wrote the paper; and X.G.C. modified the paper.

Funding: This research received no external funding.

Acknowledgments: The authors would like to thank the Natural Sciences and Engineering Research Council of Canada (NSERC) and Rio Tinto Aluminum, through the NSERC Industrial Research Chair in Metallurgy of Aluminum Transformation at the University of Québec at Chicoutimi (UQAC) for providing financial support. The authors would also like to thank Q. Li (Ryerson University) and D. Racine and P.-L. Privé (UQAC) for their assistance in the experiments.

Conflicts of Interest: The authors declare no conflict of interest.

\section{References}

1. Brammer, A.T.; Jordo, J.B.; Allison, P.G.; Barkey, M.E. Strain-controlled low-cycle fatigue properties of extruded 6061-T6 aluminum alloy. J. Mater. Eng. Perform. 2013, 22, 1348-1350. [CrossRef]

2. Abood, A.N.; Saleh, A.H.; Abdullah, Z.W. Effect of heat treatment on strain life of aluminum alloy AA6061. J. Mater. Sci. Res. 2013, 2, 51-59.

3. Yassar, R.S.; Field, D.P.; Weiland, H. Transmission electron microscopy and differential scanning calorimetry studies on the precipitation sequence in an Al-Mg-Si alloy: AA6022. J. Mater. Res. 2011, 20, $2705-2711$. [CrossRef]

4. Polat, A.; Avsar, M.; Ozturk, F. Effects of the artificial-aging temperature and time on the mechanical properties and springback behavior of AA6061. Mater. Technol. 2015, 49, 487-493. [CrossRef]

5. Buha, J.; Lumley, R.N.; Crosky, A.G. Microstructural development and mechanical properties of interrupted aged Al-Mg-Si-Cu alloy. Metall. Mater. Trans. A 2006, 37, 3119-3130. [CrossRef]

6. Haji, Z.N. Low cycle fatigue behavior of aluminum alloys AA2024-T6 and AA7020-T6. J. Eng. Sci. 2010, 22-23, 127-137.

7. Sharma, V.; Rao, G.; Sharma, S.; George, K. Low cycle fatigue behavior of AA2219-T87 at room temperature. Mater. Perform. Charact. 2014, 3, 103-126. [CrossRef]

8. Hidayetoglu, T.K.; Pica, P.N.; Haworth, W.L. Aging dependence of the bauschinger effect in aluminum alloy 2024. Mater. Sci. Eng. 1985, 73, 65-76. [CrossRef] 
9. Wong, W.A.; Bucci, R.J.; Stentz, R.H.; Conway, J.B. Tensile and Strain-Controlled Fatigue Data for Certain Aluminum Alloys for Application in the Transportation Industry; SAE International: Warrendale, PA, USA, 1987.

10. Srivatsan, T.S.; Kolar, D.; Magnusen, P. Influence of temperature on cyclic stress response, strain resistance, and fracture behavior of aluminum alloy 2524. Mater. Sci. Eng. A 2001, 314, 118-130. [CrossRef]

11. Borrego, L.P.; Abreu, L.M.; Costa, J.M.; Ferreira, J.M. Analysis of low cycle fatigue in almgsi aluminium alloys. Eng. Fail. Anal. 2004, 11, 715-725. [CrossRef]

12. Lapovok, R.; Loader, C.; Torre, F.H.D.; Semiatin, S.L. Microstructure evolution and fatigue behavior of 2124 aluminum processed by ECAE with back pressure. Mater. Sci. Eng. A 2006, 425, 36-46. [CrossRef]

13. Jogi, B.F.; Brahmankar, P.K.; Nanda, V.S.; Prasad, R.C. Some studies on fatigue crack growth rate of aluminum alloy 6061. J. Mater. Process. Technol. 2008, 201, 380-384. [CrossRef]

14. Tsuyoshi, T.; Sasaki, K. Low cycle thermal fatigue of aluminum alloy cylinder head in consideration of changing metrology microstructure. Procedia Eng. 2010, 2, 767-776. [CrossRef]

15. Zhu, M.; Jian, Z.; Yang, G.; Zhou, Y. Effects of T6 heat treatment on the microstructure, tensile properties, and fracture behavior of the modified A356 alloys. Mater. Des. 2012, 36, 243-249. [CrossRef]

16. Fan, K.L.; He, G.Q.; Liu, X.S.; Liu, B.; She, M.; Yuan, Y.L.; Yang, Y.; Lu, Q. Tensile and fatigue properties of gravity casting aluminum alloys for engine cylinder heads. Mater. Sci. Eng. A 2013, 586, 78-85. [CrossRef]

17. Nandy, S.; Sekhar, A.P.; Kar, T.; Ray, K.K.; Das, D. Influence of ageing on the low cycle fatigue behaviour of an Al-Mg-Si alloy. Philos. Mag. 2017, 97, 1978-2003. [CrossRef]

18. Su, L.; Lu, C.; Deng, G.; Tieu, A.K.; Sun, X. Microstructure and mechanical properties of 1050/6061 laminated composite processed by accumulative roll bonding. Rev. Adv. Mater. Sci. 2013, 33, 33-37.

19. Osten, J.; Milkereit, B.; Schick, C.; Kessler, O. Dissolution and precipitation behaviour during continuous heating of Al-Mg-Si alloys in a wide range of heating rates. Materials 2015, 8, 2830-2848. [CrossRef]

20. Edwards, G.A.; Stiller, K.; Dunlop, G.L.; Couper, M.J. The precipitation sequence in Al-Mg-Si alloys. Acta Mater. 1998, 46, 3893-3904. [CrossRef]

21. Ozturk, F.; Sisman, A.; Toros, S.; Kilic, S.; Picu, R.C. Influence of aging treatment on mechanical properties of 6061 aluminum alloy. Mater. Des. 2010, 31, 972-975. [CrossRef]

22. Liu, K.; Chen, X.G. Development of Al-Mn-Mg 3004 alloy for applications at elevated temperature via dispersoid strengthening. Mater. Des. 2015, 84, 340-350. [CrossRef]

23. Ebrahimi, R.; Pardis, N. Determination of strain-hardening exponent using double compression test. Mater. Sci. Eng. A 2009, 518, 56-60. [CrossRef]

24. Abu-Haiba, M.S.; Fatemi, A.; Zoroufi, M. Creep deformation and monotonic stress-strain behavior of haynes alloy 556 at elevated temperatures. J. Mater. Sci. 2002, 37, 2899-2907. [CrossRef]

25. Suresh, S. Fatigue of Materials; Cambridge University Press: Cambridge, UK, 2006.

26. Wang, Z.; Laird, C. Relationship between loading process and masing behavior in cyclic deformation. Mater. Sci. Eng. A 1988, 101, L1-L5. [CrossRef]

27. Christ, H.J.; Mughrabi, H. Cyclic stress-strain response and microstructure under variable amplitude loading. Fatigue Fract. Eng. Mater. Struct. 1996, 19, 335-348. [CrossRef]

28. Mirza, F.A.; Chen, D.L.; Li, D.J.; Zeng, X.Q. Low cycle fatigue of an extruded Mg-3Nd-0.2Zn-0.5Zr magnesium alloy. Mater. Des. 2014, 64, 63-73. [CrossRef]

29. Xue, L. A unified expression for low cycle fatigue and extremely low cycle fatigue and its implication for monotonic loading. Int. J. Fatigue 2008, 30, 1691-1698. [CrossRef]

30. Lam, P.C.; Srivatsan, T.S.; Hotton, B.; Al-Hajri, M. Cyclic stress response characteristics of an aluminummagnesium-silicon alloy. Mater. Lett. 2000, 45, 186-190. [CrossRef]

31. Calabrese, C.; Laird, C. Cyclic stress-Strain response of two-phase alloys Part I. Microstructures containing particles penetrable by dislocations. Mater. Sci. Eng. 1974, 13, 141-157. [CrossRef]

32. Bhat, S.P.; Laird, C. High temperature cyclic deformation of precipitation hardened alloy-I. Partially coherent precipitates. Acta Metall. 1979, 27, 1861-1871. [CrossRef]

33. Song, M.S.; Ran, M.W.; Kong, Y.Y.; Yan, D.Y. Low cycle fatigue behavior of cast A356 aluminum alloys. Chin. J. Nonferr. Met. 2011, 21, 538-545.

34. Tian, D.D.; Liu, X.S.; He, G.Q.; Shen, Y.; Lv, S.Q.; Wang, Q.G. Low cycle fatigue behavior of casting A319 alloy under two different aging conditions. Mater. Sci. Eng. A 2016, 654, 60-68. [CrossRef] 
35. Mirza, F.A.; Chen, D.L. Fatigue of magnesium alloys. In Aerospace Materials Handbook; Zhang, S., Zhao, D.L., Eds.; CRC Press: Boca Raton, FL, USA; Taylor\& Francis: New York, NY, USA, 2013; pp. 647-698.

36. Begum, S.; Chen, D.L.; Xu, S.; Luo, A.A. Strain-controlled low-cycle fatigue properties of a newly developed extruded magnesium alloy. Metall. Mater. Trans. A 2008, 39, 3014-3026. [CrossRef]

(c) 2018 by the authors. Licensee MDPI, Basel, Switzerland. This article is an open access article distributed under the terms and conditions of the Creative Commons Attribution (CC BY) license (http://creativecommons.org/licenses/by/4.0/). 